\title{
Impedance Characteristics of Pulsed Atmospheric Electrical Discharge in Spherical Plasma Switch
}

\author{
Abdulretha S. Hasaani* \\ Abdalhasen A. Khdayeir* \\ Ala' F. Ahmed* \\ Received 3, January, 2011 \\ Accepted 20, May, 2011
}

\begin{abstract}
:
A number of pulsed experiments have been carried out using a high-voltage circuit containing R,L, and $\mathrm{C}$ in certain arrangements. A spherical spark gap of steel electrodes was used as a high-current switch operated by a voltage of up to $8 \mathrm{kV}$ and triggered in both self-triggering and third-electrode triggering modes.

Current measurements were carried out by using both current-viewing resistor and Rogowski coils designed for this purpose. Typical current waveforms have shown obvious dominating inductance effect of the circuit components in an underdamped oscillation.

The behavior of the circuit impedance was studied by recording both pulsed current peaks and the charging voltages when currents of up to $2.5 \mathrm{kA}$ were recorded. The duration of these current pulses were found to extend between $0.1 \mu \mathrm{s}$ and $0.3 \mu \mathrm{s}$ depending on the values of the circuit components as well as the spacing of the spark gap electrodes along which the plasma propagates at atmospheric pressure. Over the whole range of experimental conditions, the average nominal impedance values were ranged between (2-10) $\Omega$ depending on the gap and circuit parameters. Typical damage patterns were observed with average diameters of up to $8.3 \mathrm{~mm}$ on the high voltage electrode and $10.5 \mathrm{~mm}$ on the grounded sphere resulting from accumulative discharges and power dissipation within the gap.
\end{abstract}

Key words: Plasma switch, Spark gap, Pulsed discharge.

\section{Introduction:}

Pulsed power technology (PPT) has been used in a wide range of applications including lasers [1], generation of relativistic electron beams for high power microwaves [2], environment [3], and industry [4]. In PPT, different high voltage switches [5] have been used as key components to transfer electrical energy from the storage unit to the load. Plasma switches are among these switching devices, which can potentially transport high electrical currents at relatively low power dissipation with controllable repetition rate. These plasma switches cover thyratrons, pseudospark, and spark gaps [6-8].

Because of their simple design and construction, low cost, and capability of current le

vel control, spark gaps have stimulated interests in a number of research activities [9-14]. In these studies, a number of operating parameters was investigated including repetition rate, discharge region of operation, electrode erosion, gas pressure, and damping conditions of the output signals. [9].

At particular gas pressure $\mathrm{P}$ and electrode spacing $\mathrm{d}$, the product pd is

* College of Science, University of Baghdad 
known as the sparking parameter and is characterized by the Paschen curve for each gas and g Department of Physics, eometry [10]. The mechanism involves the production of plasma and the propagation of plasma particles between the electrodes of the spark gap giving rise to a high current flow through the circuit. Characteristic current-voltage curves can then be deduced from the output signals after recording the charging voltage of the capacitor or the energy storage unit.

Previous experiments [11-17] were carried out to study the effect of the breakdown conditions and the plasma characteristics where breakdown could be preceded by corona stabilization in non-uniform electric field geometry. Such studies establish a correlation scheme between charged particle density and its governing parameters. Moreover, these experiments intended to select a method for triggering for a single and multiple spark gap. However, electrode surface flashover was found to be adequate to operate typical spark gaps with certain geometry and gas pressure.

One of the prime objectives of this paper is to investigate the temporal behavior of the impedance of an atmospheric pressure spark gap with spherical electrodes. Analysis of the discharge current oscillograms under various damping conditions was carried out as two triggering techniques were followed after being designed for these experiments. Such analysis may establish a scope for understanding the efficiency of switching since it is governed by the gap resistively and breakdown voltage level.

\section{Materials and Methods:}

A group of capacitors was stacked into a bank to deliver a capacitivelystored energy of variable level. This energy was controlled by the amount of charging voltage which was applied from a dc-power supply as shown in Fig.(1). The experimental procedure starts by setting the electrode spacing of the spark gap (d) measured by a calibrated filler gauge.

To establish a proper damping conditions in the circuit, the capacitor bank $(\mathrm{C}=39 \mu \mathrm{F})$ was charged through a current-limiting resistance to variable voltages. For each specified voltage, a discharge current was recorded when the spark gap had been triggered via a particular mode. To make sure that there was no additional inductance coupled to the circuit from the triggering device, a number of experiments was carried out by spark gap self-triggering (self breakdown). In such conditions, the bank erected to a certain voltage level enough to establish self-breakdown followed by the transport of discharge current.

The charging voltage was monitored by a (1000:1) standard high voltage probe, which was connected to a digital multimeter. The discharge current was recorded on a digital double beam storage Oscilloscope by using a cylindrical current-viewing resistance (CVR) (current shunt) which was designed and constructed for this purpose. For cross-correlated measurements of the discharge current, Rogowski coils also threaded into the grounded connection of the RLC circuit. These coils were designed, constructed, and calibrated to record the pulsed discharge currents [18]. 


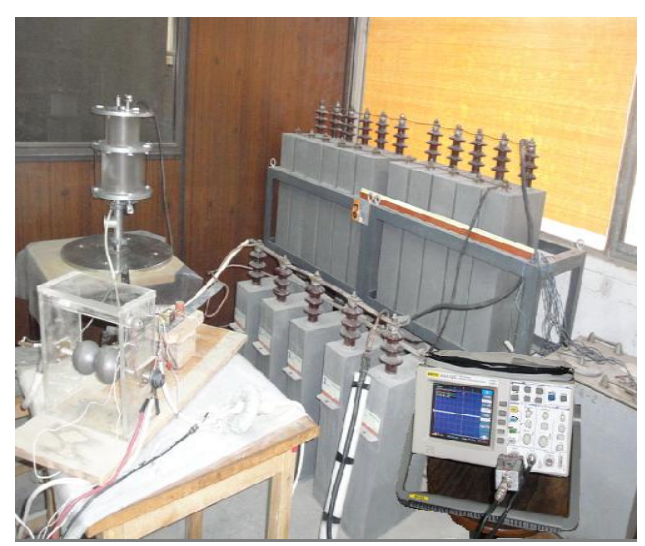

(a)

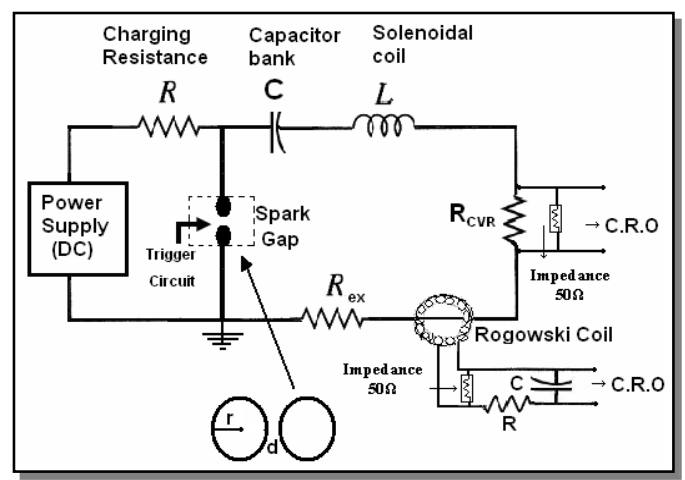

(b)

Fig. (1) Experimental setup (a) photograph of the pulsed RLC circuit (b) Equivalent circuit

A $50 \Omega$ matching coaxial impedance were connected to each input of the oscilloscopes to any possible mismatch in signal propagation. A proper RC-integration circuit was constructed and connected to the

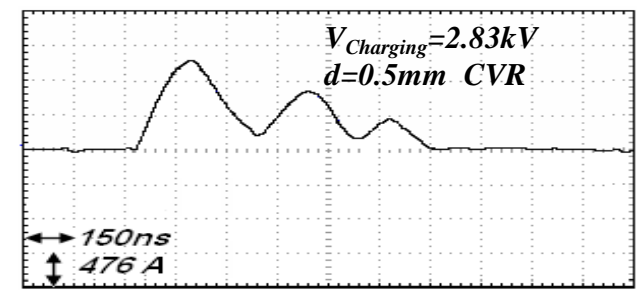

(a)

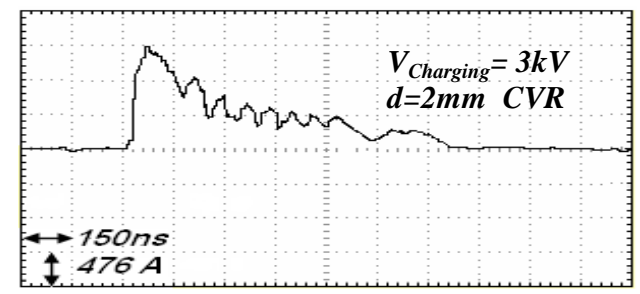

(c) output of the Rogowski coil to measure the current rather than its rate of change.

\section{Results and Discussion:}

Exploring the current-voltage and current-time characteristics of the operational pulsed circuit, a number of preliminary experiments was carried out using the circuit shown in Fig.(1b). By operating the spark gap with selfbreakdown mode, measurements of the time required for charging the C-bank up to a voltage sufficient for selfbreakdown (charging time) were necessary to test the reliability of the circuit as well as the range of reproducibility. As was discussed in the proceeding section, current measurements were carried out by both CVR and Rogowski coils. Therefore, for each charging voltage, there was a corresponding time-varying discharge current signal to be inspected. Fig.(2) shows four typical oscillograms obtained for a spark gap spacing of 0.5 $\mathrm{mm}$ using self-triggering mode (a and b ) and third-electrode triggering mode (c and $\mathrm{d}$ ). With a charging voltage of $2.8 \mathrm{kV}$, a typical peak discharge current of $(1.25 \pm 0.05) \mathrm{kA}$ could be obtained for self triggering while a peak

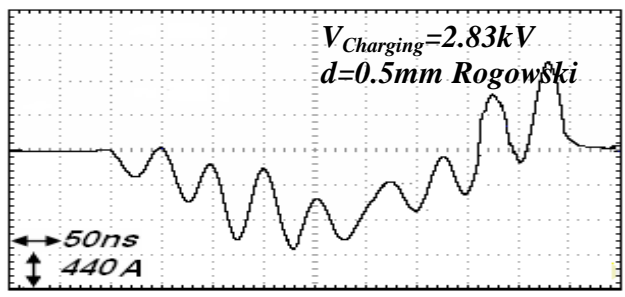

(b)

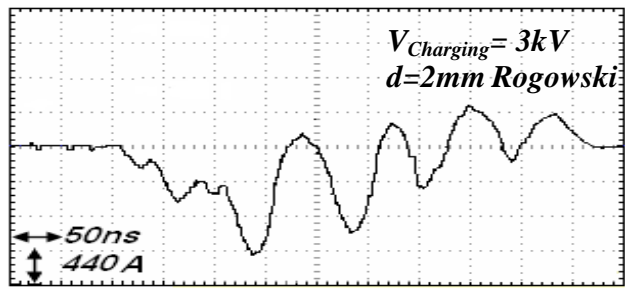

(d)

Fig. (2) Typical discharge current oscillograms recorded by CVR and Rogowski coil; ( a, b) self- triggering and $(c, d)$ third-electrode triggering 
current value of $(1.35 \pm 0.05) \mathrm{kA}$ was obtained with a $3 \mathrm{kV}$ charging voltage in the other mode of triggering with longer spacing $(2 \mathrm{~mm})$. The features of the signals illustrate the effect of both triggering mode and gap spacing on the damping conditions of the circuit. A graphical representation of the charging and discharging times is shown in Fig.(3). The performance of the pulsed circuit may be envisaged by the ratio (discharging time/charging time) for self-breakdown condition. The differences in current values may be imposed by the (inductance/resistance) ratio of Rogowski coil which is reasonably acceptable in pulsed techniques [18].

A linear dependence of the breakdown voltage on the spark gap spacing is shown in Fig.(4) . This behavior demonstrates that these experiments were run along the right side of the Paschen curve with a nonthermal plasma generated within the gap at atmospheric pressure. At this pressure the plasma is highly conductive as spark ignition proceeds to arcing which may impose a shrinkage of both normal and abnormal glow regions in the current- voltage characteristic curve of the discharge [19].

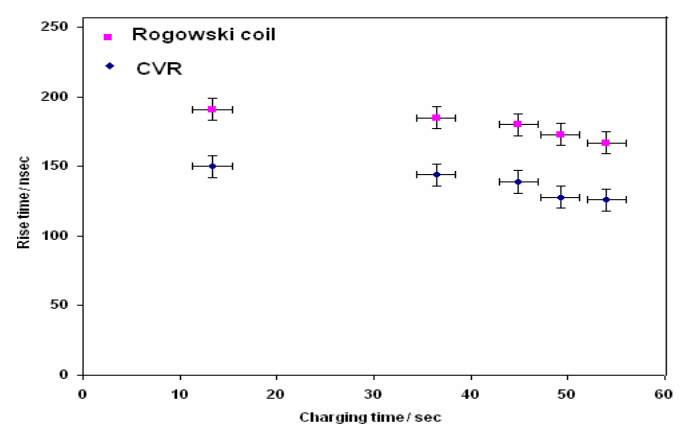

Fig. (3) Rise time of the pulse as a function of charging time for Selfbreakdown triggering

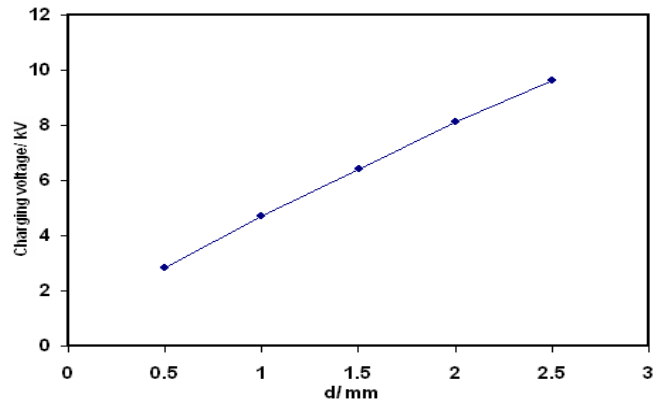

Fig. (4) Charging voltage versus gap spacing for self-breakdown

In Fig.(5), a typical discharge current charging voltage characteristic curve is shown when both CVR and Rogowski coil measurements of the current are demonstrated .

Two regions may be distinguished in this curve; one region showing a gradual increase in the current with raising the charging voltage and the other, i.e., after a charging voltage of about $7 \mathrm{kV}$, shows a very slight change in the current which illustrates that there is no additional source of charged particles including that from secondary emission for the $2 \mathrm{~mm}$ gap spacing where the electrical power is dissipated - To investigate the impedance behaviour of the spark gap, a number of parameters were considered including the damping conditions, gap spacing and pulse duration. Two approaches were adopted to analyze the results of the output current signals. The first was to take a number of oscillograms for various gap spacing. A number of current values was extracted from each oscillogram that corresponds to a certain d. For a number of $\mathrm{d}$-values ranged from 0.5 $\mathrm{mm}$ to $2.5 \mathrm{~mm}$, the nominal impedance $\mathrm{Z}$ (charging voltage /discharge current) was plotted as a function of the rise time of each 


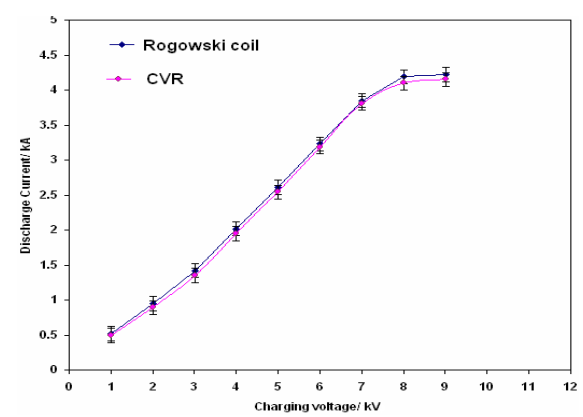

Fig. (5) Typical discharge current-charging voltage characteristic curve for $\mathrm{d}=\mathbf{2} \mathrm{mm}$ under third-electrode triggering mode

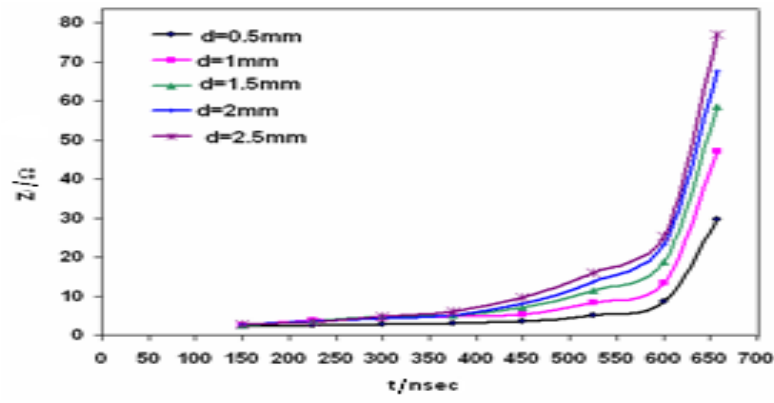

(a)

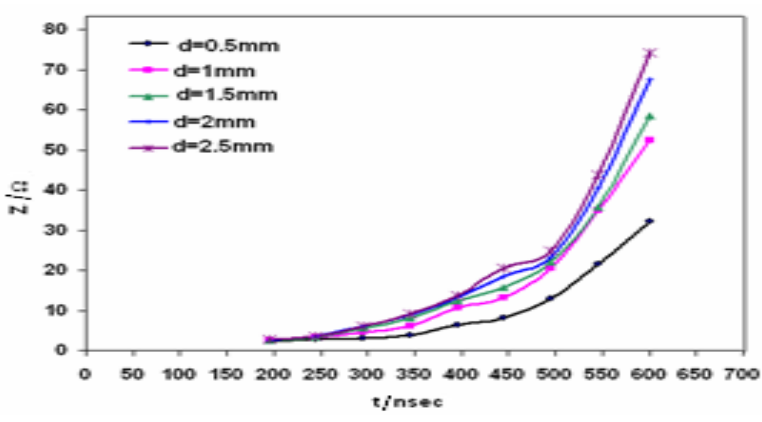

(b)

Fig. (6) Impedance as a function of current rise- time for self-breakdown mode (a) CVR (b) Rogowski coil, extracted from the same current oscillogram pronounced current peak on the same oscillogram under self-breakdown conditions as shown in Fig.(6) .

The same trend of behaviour is obvious in both CVR and Rogowski coil measurements of the current, Fig.(6a and $b$ ). The values of $\mathrm{Z}$ increases with enlarging $d$ while the impedance shows a prompt increase with rise time as a result of current degrading as the signal damps out due to the finite closure time of the spark gap [9].

The other way of analysis was to take the first half cycle of each current signal in a number of oscillograms and

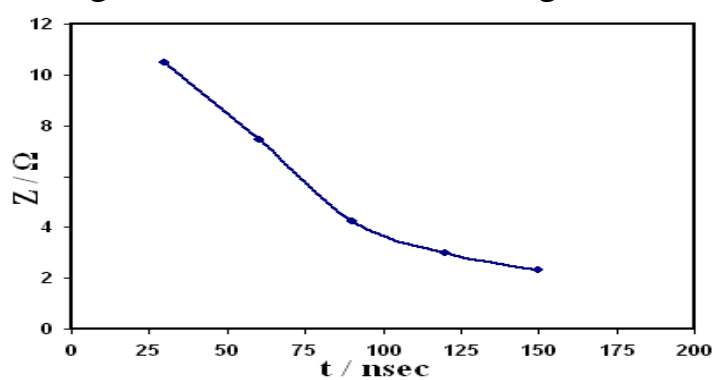

(a) record the peak value and its rise time. Through a similar manner to that discussed above, the values of $\mathrm{Z}$ were deduced and plotted as a function of the corresponding value of the rise time as shown in Fig. (7). It can be concluded from Figs.(6 and 7) that time-varying impedance exists due to the inductance and resistivity of the spark gap as well as the expansion of plasma channels along the spacing $\mathrm{d}$. The gap closure time may be taken as the time required for the plasma to expand between the two gap electrodes resulting in an impedance collapse.

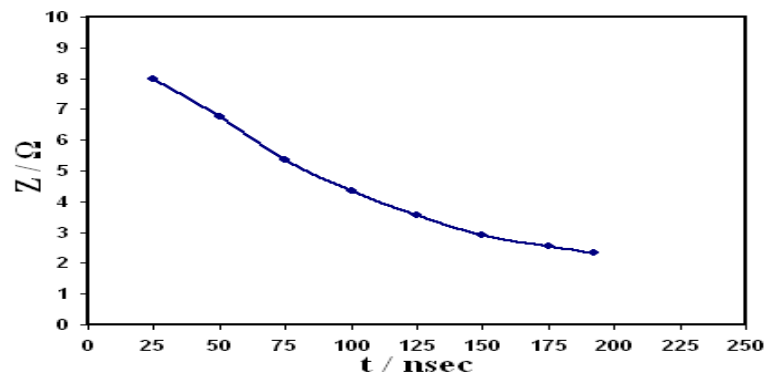

(b)

Fig. (7) Typical impedance behaviour for self-breakdown mode at $\mathrm{d}=0.5 \mathrm{~mm}$ (a) CVR (b) Rogowski coil, extracted from various current oscillograms 


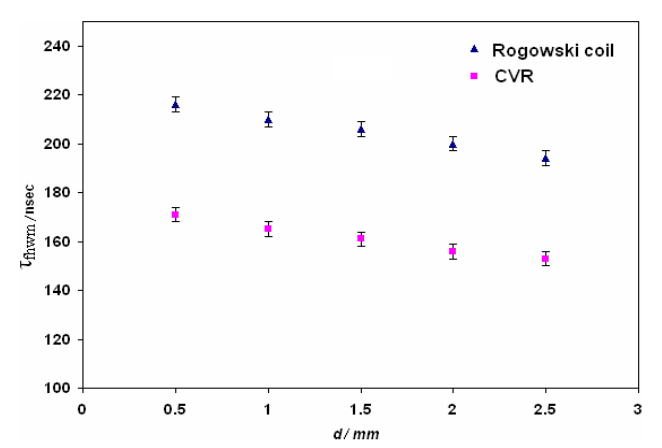

Fig. (8)Variation of time of full width at the half maxima $\tau$ fhwm with gap spacing

gap resulted in an erosion on the surfaces of both electrodes as shown in Fig.(9). Erosion rate may increase nonlinearly with upgrading current levels [14].

The damage pattern created on the two surfaces has the dimensions of about $8.3 \mathrm{~mm}$ on the high voltage electrode and $10.5 \mathrm{~mm}$ on the grounded electrode. The expansion of plasma particles towards the grounded electrode and space change effect may be responsible for this difference in pattern dimensions.

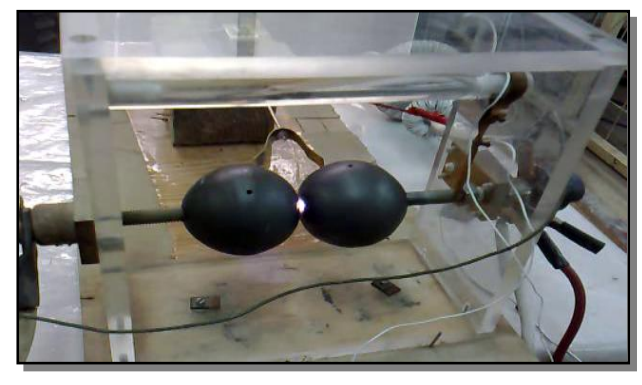

Over the whole range of experimental conditions being undertaken, the average values of an overall nominal impedance were found in the range (2$10) \Omega$ depending on the gap and circuit parameters.

Taking the full-width at the half maxima of current signals obtained for gap spacing ranged from $0.5 \mathrm{~mm}$ to $2.5 \mathrm{~mm}$, a graphical representation demonstrates that the time required for short-circuiting the gap shows slight fluctuations as shown in Fig.(8) . Such behaviour illustrates the effect of damping conditions created within the gap throughout the time interval of plasma expansion, i.e., oscillation conditions need more than $\boldsymbol{\tau}_{f w h m}$ to damp out for this circuit which is slightly underdamped.

Over a number of experiments conducted with the spark gap and by having an accumulative number of shots exceeding one thousand, power dissipation within the

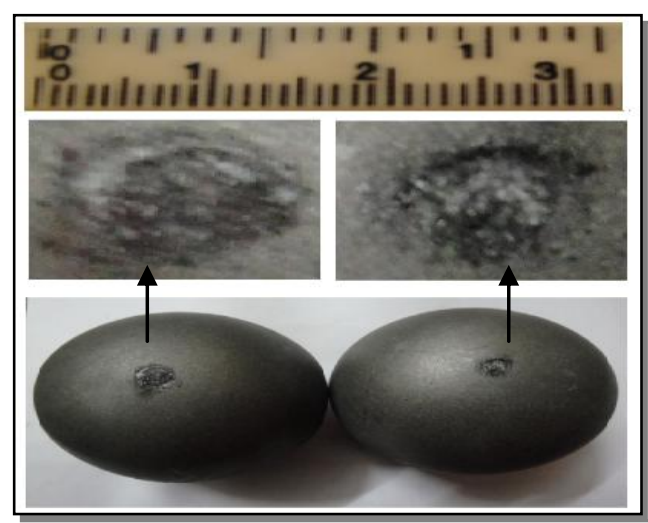

Fig. (9) A photograph of the experimental spark gap showing the formation of spark and damage patterns

\section{Conclusion:}

The time-varying impedance of an atmospheric-pressure spark gap of spherical electrodes has been studied with pulsed electric field of a wide range of strength level governed both by the applied voltage and gap parameters. Experiments operated with self-breakdown mode and typically with gap length ranged between $0.5 \mathrm{~mm}$ and $2.5 \mathrm{~mm}$ showed a number of characteristic curves illustrating the dependence of the discharge current with respect to other circuit parameters and the expansion of nonthermal plasma channels between the spark gap electrodes. The triggering method was 
found to have an effect on the discharge current pulses monitored by both current viewing shunt and Rogowski coil. Damage patterns on the surfaces of the gap electrodes were photographed as they resulted from power dissipation within the gap controlled by discharge current levels.

\section{References:}

[1] Nunnally W. C., Lewis R., Allen F., Hawkins S., Holmses C., Sarnpayan S., and Capopraso G.. 2005." Experiments with UV laser triggered spark gaps in a stacked Blumlein system ", IEEE Int. Pulsed Power Conference (Monterey, Ca, USA Jurnol,: 2(5): $14-17$.

[2] Hasaani A. S.,. 1993. " On The Temporal Behavior of Pulsed Relativistic Electron Beam Diodes ", Engineering and Technology, 8 (4): 56 - 69.

[3] Abou-Ghazala A. , Katsuki S. , Schoenbach , Dobbs F. and Moreira K. . 2002. "Bacterial Decontamination of water by means of pulsed Corona Discharges" IEEE Transaction on Plasma Science , 30(4) :1449 1453.

[4] Hidenori A., Takashi S., Takao N., Koichi T.i, Yasushi M., and Naoyuki S.. 2007 "Industrial Applications of Pulsed Power Technology", IEEE Tran. on Diele. and Elect. Insu.. 14(5): 1051 -1064.

[5] Esin Bengisu S. .2008." Gaseous Discharges and their Applications As High Power Plasma Switches for Compact Pulsed Powers Systems, MSc. thesis, University of Auburn : p 57.

[6] Hasibur Rahaman. 2007. "Investigation of a High-Power, High-Pressure Spark Gap Switch with High Repetition Rate", PhD. thesis, University ErlangenNürnberg: $\mathrm{p} 151$.
[7] Meena BL., Rai SK., Tyagi MS., Pal UN., Kumar M. and Sharma AK. . 2010. "Characterization of high power Pseudospark Plasma Switch (PSS)" , Journal of Physics: Conference Series 2(8), 121.

[8] Hasibur R., Byung-Joon L., Jürgen U., Robert S., Klaus F., Nam S.H. . 2007 ."A spark gap switch with very high repetition rate", $28^{\text {th }}$ ICPIG, July 15-20, , Prague, Czech Republic: 1496 - 1498.

[9] Horacio B., Cesar M. and Roberto V.. 1993. " Measurement of the time -evolution of averaged impedances in small atmospheric pressure spark- gap", Meas. Sci. Technol. , (4) : 952 -956.

[10] Hasaani A. S., " Correlation of Paschen Parameters in Magnetized argon Plasma".2010. Iraqi , J. Phys. , (8)11: 95-101.

[11] Krasika Ya. E., Chirko K., Gleizer J.Z., Krokhmal A., Dunaevsky A., and Felsteiner J. . 2002. "Application of a ferroelectric plasma cathode as a high-current switch", Eur. Phys. J. D, (19): 89-95.

[12] Frey W., Sack M., Wuestner R. and Muelle G.r. .2009. "GasInsulated Self-Breakdown Spark Gaps: Aspects on Low-Scattering and Long-Lifetime Switching", Acta Physica Polonica A, (115) 6: 1016- 1018.

[13] Beveridge J. R., MacGregor S. J., Given M. J., Timoshkin I. V. . 2009. "A Corona-stabilised Plasma Closing Switch", IEEE Trans. Dielectr. Electr.1 Insul., (6)4: 948955.

[14] Liu Z., Pemen A. J. M., Van Heesch E. J. M., Yan K., Winands G. J. J., Pawlok D. B. . 2008. "A Multiple-switch Technology for High-power Pulse Discharging", 11th International Conference on Electrostatic Precipitation. : 704708. 
[15] Max Chung, and Erich Kunhardt. 2006. " Novel Trigger Mechanism High-Power Switch: The Electrostatic Plasma Injection Switch", IEEE Transitions On Plasma Science, (34) 5: 16261639.

[16] Peterkin F. E. and Wisiiams P.F.. 1988. "Physical mechanism of triggering in trigatron spark gaps", Appl. Phys. Lett. (53)3: 182-184.

[17] Georgescu N. . 2008. "High Voltage Pulsed, Cold Atmospheric Plasma Jets: Electrical Characterization ", Romanian
Reports in Physics, (60)4: 10251032.

[18] Hasaani A.S.. 1993.

"Experimental Studies of

Differtiating Rogowski Coils",

J.Math . and Phys. ,(13)2 : 160176.

[19] Andreas S., James Y. Jeong, Steven E. Babayan, Jaeyoung P., Gary S. Selwyn and Robert F. Hicks. 1998. "The Atmospheric Pressure Plasma Jet : A Review and Comparison to Other Plasma Sources", IEEE Transitions On Plasma Science, (26)6: 1685-1694.

\section{خصائص ممانعة تفريغ كهربائي نبضي في مفتاح بلازما كروي تحت الضغط

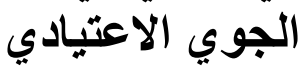

آلاء فاضل احد الراشديث

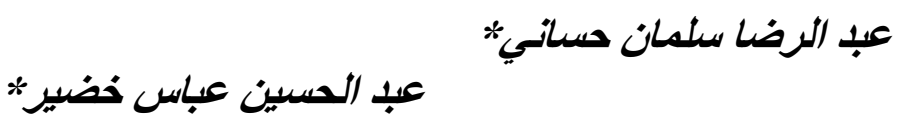

*قسم الفيزياء/ كلية العلوم/ جامعة بغداد

الخلاصة: أستخدمت دائرة فولتية نبضية عالية تحتوي على مقاومة ومتسعة ومحاثة لاجراء تجارب تفريغ

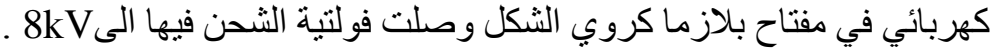

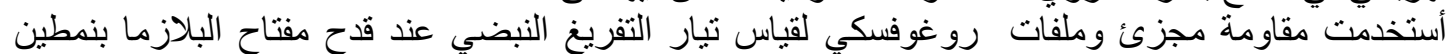

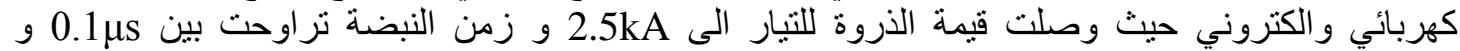
$.0 .3 \mu \mathrm{s}$

اوجدت التجارب وجود سلوك حثي سائد في الدائرة معتمدا على قيمة مكونات الدائرة وسلوك البلازما المنتقلة

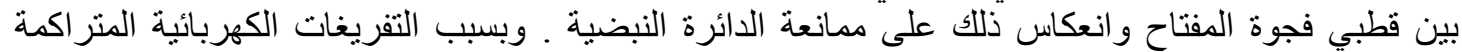

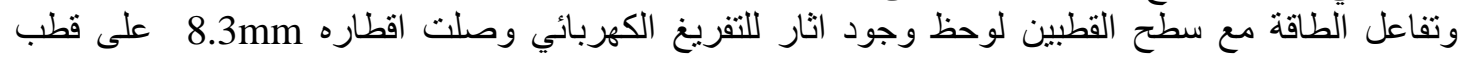

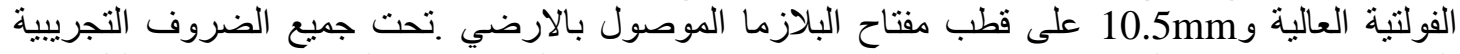

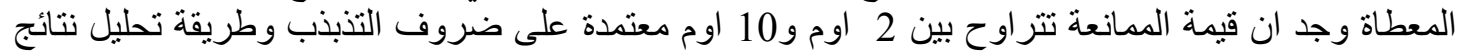
اشتار ات تبار التفريغ الكهربائي. 